\title{
Effects of 10 known or suspected spindle poisons in the in vitro porcine brain tubulin assembly assay
}

\author{
Martin Brunner, Silvio Albertini ${ }^{1,2}$ and \\ Friedrich E.Würgler \\ Institute of Toxicology, Swiss Federal Institute of Technology and \\ University of Zürich, Schorenstrasse 16, CH-8603 Schwerzenbach and \\ ${ }^{2}$ Pharmaceutical Research, Department of Toxicology, PF/TOX Building \\ 86/601, F.Hoffmann-La Roche Ltd, CH-4002 Basel, Switzerland. \\ ${ }^{1}$ To whom correspondence should be addressed
}

We tested the 10 known or suspected spindle poisons (colchicine, econazole nitrate, chloral hydrate, hydroquinone, diazepam, thiabendazole, cadmium chloride, thimerosal, pyrimethamine and vinblastine) of the coordinated EEC programme for induction of aneuploidy with the in vitro porcine brain tubulin assembly assay. The influence of the compounds on different parameters [lag-phase, polymerization velocity, endabsorption (steady-state level), reversibility, influence on disassembly at $4^{\circ} \mathrm{C}$ ] was evaluated. Colchicine [IC $\mathrm{IC}_{30}(30 \%$ inhibition concentration): $0.002 \mathrm{mM})$, vinblastine $\left(\mathrm{IC}_{30}: 0.002 \mathrm{mM}\right)$, thimerosal $\left(\mathrm{IC}_{30}: 0.03 \mathrm{mM}\right)$, thiabendazole $\left(\mathrm{IC}_{30}: 0.5 \mathrm{mM}\right)$ and chloral hydrate $\left(\mathrm{IC}_{30}: 60 \mathrm{mM}\right)$ led to an inhibition of tubulin assembly in vitro. No influence on the steady-state level was obtained with econazole nitrate (up to $0.1 \mathrm{mM}$ ), diazepam (up to $2.5 \mathrm{mM}$ ), cadmium chloride (up to $1 \mathrm{mM}$ ), pyrimethamine (up to $1 \mathrm{mM}$ ) and hydroquinone (up to $25 \mathrm{mM}$ ), the highest dose tested being limited either by precipitation or by reaching the maximal solubility of the compound in the solvent used. Diazepam enhanced the lag-phase and slightly reduced the polymerization velocity dose-dependently; however, all the treated test mixtures reached the same end absorption levels as the control. The influence on the disassembly process was studied at $4^{\circ} \mathrm{C}$. Microtubules treated with colchicine, econazole nitrate, diazepam, thiabendazole, cadmium chloride, thimerosal and pyrimethamine reached the same end absorption level after disassembly as the untreated control. Chloral hydrate reduced the disassembly rate but the end absorption of the control was not reached, the $30 \%$ reduction concentration being $0.25 \mathrm{mM}$. Hydroquinone at very high doses (>10 mM) stimulated the disassembly process. The in vitro tubulin assembly assay is, on the basis of this small database, an indicative pre-screening test for aneuploidy inducing chemicals which act mechanistically via interaction with tubulin and/or microtubule associated proteins, both components of the spindle apparatus.

\section{Introduction}

Aneuploidy is a particularly pressing problem in humans. Man appears unique among all investigated species in showing a particularly high level of aneuploidy. No other single type of chromosome abnormality contributes more to human ill health and suffering. Human aneuploidy has multiple consequences. These include miscarriage (abortion), infertility, congenital malformations, mental retardation and cancer. The frequency of aneuploidy in newborn humans is in the range of $0.4-0.8 \%$ (Hook and Hammerton, 1977) and 35\% of all spontaneous abortions turned out to be aneuploid (Sankaranarayanan, 1979; Jacobs and Hassold, 1980). Chromosome malsegregation may also be involved in the formation of malignant tumors (Hook, 1983). In somatic tissues, aneuploidy can play a role in tumorigenesis, i.e. by a possible participation during initiation and/or promotion/progression of malignancy or by expression of oncogenes (Tsutsui et al., 1983; Kondo et al., 1984; Evans et al., 1985).

The mechanisms and the cellular targets leading to the induction of aneuploidy are to a large extent different from those leading to gene and chromosomal mutations where DNA is involved as the principal target.

The mechanisms leading to chromosomal malsegregation are little understood. Furthermore, there are relatively few chemicals that have been tested in a comprehensive battery of aneuploidy assays (Waters et al., 1986). The European Economic Communities (EEC) initiated a coordinated programme with the aim of developing a database on aneuploidy (Parry, 1987; Parry et al., 1990). The assay systems included in the programme range from the polymerization of tubulin in vitro to the production of aneuploid gametes in intact animals.

Tubulin and microtubule associated proteins (MAPS and Tau; for review, see Dustin, 1984) are the main constituents of the spindle. In spite of the biochemical characterization of the spindle structures, the molecular mechanisms of mitosis are still under investigation. Mammalian brain tubulin has been studied in great detail, and much is known about its behaviour in vitro (Timasheff, 1979; Gaskin, 1982). Different studies compared the chemical induction of aneuploidy in a cellular system with the influence of the same chemicals on an in vitro mammalian brain tubulin system (Albertini et al., 1985, 1988a,b, 1989; Gröschel-Stewart et al., 1985; Hartley-Asp et al., 1985; Sharp and Parry, 1985; Zimmermann et al., 1985a,b, 1986).

In the present study, results were obtained with the 10 core chemicals of the coordinated EEC Programme, previously tested in Saccharomyces cerevisiae D61.M for chromosome malsegregation (Albertini, 1990), by using the in vitro porcine brain tubulin assembly. To investigate the influence on the disassembly process a new experimental approach was undertaken. The temperature-controlled compartment of the spectrophotometer was cooled down from $37^{\circ} \mathrm{C}$ to $4^{\circ} \mathrm{C}$ within $2 \mathrm{~min}$, thereby inducing disassembly of microtubules which were formed at $37^{\circ} \mathrm{C}$ in presence of the chemical.

Materials and methods

Chemicals

Thimerosal (Thiomersal; CASRN 54-64-8) was obtained from Serva, Heidelberg (FRG); pyrimethamine (58-14-0), vinblastine (865-21-4) and econazole nitrate (27220-47-9) from Sigma, St Louis, MO (USA); colchicine (64-86-8), cadmium chloride (10108-64-2), hydroquinone (123-31-9) and chloral hydrate (302-17-0) from Fluka Chemie AG, Buchs (Switzerland); diazepam (439-14-5) and thiabendazole (148-79-8) from F.Hoffmann-La Roche Ltd, Basel (Switzerland); dimethylsulfoxide (DMSO, 67-68-5) from Merck AG, Darmstadt (FRG). 


\section{Tubulin isolation}

Porcine brain tubulin was prepared according to Williams and Lee (1982). For the purification, two cycles of assembly and disassembly were used. The protein content of the final preparations was determined by the method of Bradford (1976). Purity of each tubulin preparation was evaluated by a slightly modified SDS-PAGE method (Laemmli, 1970; Laemmli and Favre, 1973). The preparations were stored in ice overnight and used the following day for the assembly and disassembly test.

Tubulin assembly assay

Tubulin assembly was followed photometrically by measuring the increase in absorbance at $350 \mathrm{~nm}$. PIPES buffer (100 mM, pH 6.9) with $2 \mathrm{mM}$ EGTA [ethylene glycol- $O, O^{\prime}$-bis(2-aminoethyl- $N, N, N^{\prime}, N^{\prime}$-tetraacetic acid], $1 \mathrm{mM} \mathrm{MgSO}_{4}, 2 \mathrm{mM}$ dithioerythritol and $4 \mathrm{M}$ glycerol were mixed in an ice bath with $5 \mu \mathrm{l}$ DMSO or buffer containing different amounts of the test compound and $10 \mu \mathrm{l}$ of a $50 \mathrm{mM}$ solution of GTP [guanosine-5'-triphosphate (dilithium salt)] in $10 \mathrm{mM}$ PIPES buffer. Immediately before the start of the experiment $250-350 \mu$ l of the tubulin preparation were added. The final volume of the reaction mixture was adjusted to $1.0 \mathrm{ml}$ with buffer, thoroughly mixed and poured into a cuvette placed in the temperature-controlled compartment $\left(37^{\circ} \mathrm{C}\right)$ of a recording spectrophotometer. The relative change of absorbance was followed simultaneously in five cuvettes in a five-position cuvette holder and absorbance recorded with $12 \mathrm{~s}$ intervals between each cuvette so that a given cuvette was read at 1 min intervals.

Tubulin disassembly assay

To investigate the influence of chemical compounds on the disassembly process of microtubules the following new experimental approach was conducted. After the assembly test at $37^{\circ} \mathrm{C}$ was completed, the temperature-controlled compartment was cooled down to $4^{\circ} \mathrm{C}$ within $2 \mathrm{~min}$. During the following $30-40 \mathrm{~min}$ the influence of the test compounds on the process of disassembly in the cold was followed by monitoring the change in absorbance at $350 \mathrm{~nm}$.

In vitro tubulin assay

The influence of the different compounds on the in vitro assembly kinetics of porcine brain tubulin can be studied by comparing different parameters (Fig. 1). (i)lag-phase: time elapsed until the polymerization reaches $10 \%$ of end absorption. (ii) polymerization velocity $(\mathrm{d} A / \mathrm{d} t)$ in the range between 10 and $90 \%$ of end absorption. (iii) end absorption (steady-state level): Absorbance at the end of the assembly; the $30 \%$ inhibition concentration $\left(\mathrm{IC}_{30}\right)$ of compounds inhibiting the assembly process can be calculated. (iv) depolymerization velocity ( $\mathrm{d} A^{*} / \mathrm{d} t^{*}$ ). (v) end absorption after disassembly process at $4^{\circ} \mathrm{C}$

\section{Resuits}

The results obtained with the ten chemicals evaluated are summarized in Table 1. The highest dose tested was either limited by the solubility of the test compound or by precipitation of the compound in the aqueous medium.

Out of the 10 chemicals evaluated, five led to an inhibition of the in vitro polymerization of porcine brain tubulin (Figure 2): colchicine, chloral hydrate, thiabendazole, thimerosal and vinblastine. The concentrations necessary to reduce the steadystate level by $30 \%$ covered a wide range: $0.002 \mathrm{mM}$ (colchicine and vinblastine), $0.03 \mathrm{mM}$ (thimerosal), $0.5 \mathrm{mM}$ (thiabendazole) and $60 \mathrm{mM}$ (chloral hydrate). Five compounds (econazole nitrate, hydroquinone, diazepam, pyrimethamine and cadmium chloride) had no effect on the steady-state level reached at the end of the assembly process (Figure 2). The highest 'no effect' doses for the five compounds on the steady-state level were: $0.1 \mathrm{mM}$ for econazole nitrate, $25 \mathrm{mM}$ for hydroquinone, $2.5 \mathrm{mM}$ for diazepam, $1 \mathrm{mM}$ for pyrimethamine and $1 \mathrm{mM}$ for cadmium chloride.

An enhanced lag-phase (time elapsed until the onset of tubulin polymerization) was observed after treatment with diazepam (Figure 3), thimerosal (Figure 4) and vinblastine. The other compounds had no influence on this parameter. A dose-dependent reduction of the polymerization velocity was induced by colchicine, enconazole nitrate, diazepam (Figure 3), thimerosal (Figure 4), thiabendazole (Figure 5) and vinblastine. With regard to the reversibility of the assembly process all compounds, except chloral hydrate, did not affect tubulin disassembly at $4^{\circ} \mathrm{C}$ (same end absorption after disassembly at $4^{\circ} \mathrm{C}$ as control).

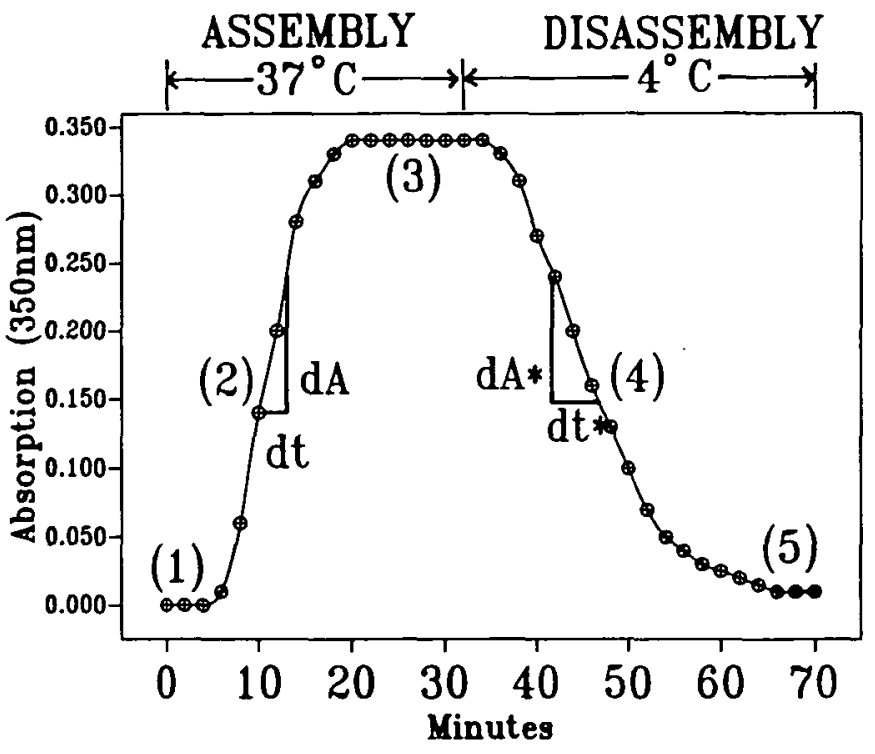

Fig. 1. Scheme of in vitro tubulin assay.

The influence of the 10 compounds on the disassembly process at $4{ }^{\circ} \mathrm{C}$ was investigated. Chloral hydrate showed a reduction in the disassembly rate (depolymerization velocity as well as the end absorption reached). The concentrations needed for reduction were much lower than those needed for a reduction of the assembly steady-state level $\left(\mathrm{IC}_{30}\right.$ assembly: $70 \mathrm{mM} ; \mathrm{IC}_{30}$ disassembly: $0.25 \mathrm{mM}$ ). Hydroquinone appears to lead to an enhancement of the depolymerization velocity at high concentrations $(>10 \mathrm{mM}$ ). All other compounds showed no interference with the disassembly process.

\section{Discussion}

Since there is unequivocal evidence that frequency of aneuploidy can be increased in experimental organisms by a variety of treatments, there is naturally a concern that human populations, if exposed to aneuploidy inducers, might suffer increased rates of aneuploidy. Extrapolation of findings from experimental organisms to man, however, is hampered by extensive differences of the cell division processes.

Difficulties may arise because the direct target of a treatment is specific to the test organism or because a treatment has an effect via secondary physiological processes which are confined to the test system.

Little is known about the mechanisms leading to chromosomal malsegregation. One specific major target is the spindle, particularly the spindle microtubules. The in vitro tubulin assembly assay could, therefore, be employed as a test system for differentiating aneuploidy inducing chemicals acording to their action mechanisms.

In the present study, the 10 core chemicals which were selected for an EEC coordinated programme on aneuploidy systems on the basis of their known ability to affect specific target organelles were tested in the in vitro porcine brain tubulin asembly assay.

As summarized in Table $\Pi$ all compounds previously proposed to act via spindle/tubulin were positive in our in vitro system, but showed considerable differences in their mode of action. Compounds suggested to be acting via other mechanisms were negative.

Induction of aneuploidy in different test systems by the 10 compounds of the EEC study is discussed in several recent 
Table I. Summary of the effects of the 10 EEC aneuploidy programme compounds on tubulin assembly

\begin{tabular}{|c|c|c|c|c|c|c|c|}
\hline Compound & \multicolumn{6}{|c|}{ Tubulin assembly test ${ }^{a}$} & Disassembly assay ${ }^{b}$ \\
\hline Econazole nitrate & 0 & $\mathbf{w R}$ & 0 & $\mathrm{Y}$ & - & $0.001-0.1$ & $\mathrm{~N}$ \\
\hline Chloral hydrate & $\mathrm{R}(>20 \mathrm{mM})$ & $\mathrm{wE}(>20 \mathrm{mM})$ & $R(>20 \mathrm{mM})$ & $\mathbf{N}$ & 60 & $0.01-100$ & $\mathrm{R}\left(\mathrm{IC}_{30}: 0.25 \mathrm{mM}\right)$ \\
\hline Hydroquinone & 0 & 0 & 0 & $\mathrm{Y}$ & - & $0.005-25$ & prob. $\mathrm{E}(>10 \mathrm{mM})$ \\
\hline Cadmium chloride & 0 & 0 & 0 & $\mathrm{Y}$ & - & $0.005-1$ & $\mathbf{N}$ \\
\hline Thimerosal & $\mathrm{E}$ & $\mathbf{R}$ & $\mathbf{R}$ & $\mathrm{Y}$ & 0.03 & $0.005-0.5$ & $\mathbf{N}$ \\
\hline Pyrimethamine & 0 & 0 & 0 & $\mathbf{Y}$ & - & $0.001-1$ & $\mathbf{N}$ \\
\hline Vinblastine & $\mathrm{E}$ & $\mathbf{R}$ & $\mathbf{R}$ & $\mathbf{N}$ & 0.002 & $0.001-0.1$ & ND \\
\hline
\end{tabular}

${ }^{a} 0$, no effect; $R$, reduction; wR, weak reduction; E, enhancement; $Y$, yes; $N$, no; ND, not determined

bEffect on depolymerization velocity or end absorption after disassembly.

publications (Miller and Adler, 1989; Albertini, 1990; Xu and Adler, 1990).

\section{Colchicine}

Our in vitro results obtained with colchicine, the best known of all microtubule poisons, are in agreement with published results (Kilmartin, 1981; Dustin, 1984; Wallin et al., 1988). Colchicine inhibits the formation of microtubules by binding to tubulin dimers. Once microtubules have formed there does not seem to be an interaction and the disassembly process is not affected. The observed disappearance of microtubules could, therefore, result from a continued disassembly and disability to form microtubules or from slowing down the process of assembly (Dustin, 1984). Our results obtained with the disassembly assay support this hypothesis. Surprisingly, the number of studies (up to 1986) providing results acceptable to the Committee for Aneuploidy (Gene-Tox programme) for colchicine is extremely meager (for details see special issue Mutation Research 167 (1986) 1-188). Furthermore, conflicting data in plants are reported. More recently, Miller and Adler (1989) reported mitotic arrest and C-mitotic effects in mouse bone marrow cells after treatment with colchicine. In S.cerevisiae no induction of chromosomal malsegregation was reported by Albertini (1990) and Parry et al. (1990). These negative findings in yeast are not surprising, because the binding of colchicine to yeast tubulin is $>1000$-fold weaker than the binding to mammalian tubulin (Kilmartin, 1981).

\section{Chloral hydrate}

Chloral hydrate, a metabolite of trichloro- and tetrachloroethylene, both potential human carcinogens, causes an inhibition of the assembly as well as the disassembly process. The disassembly process at $4^{\circ} \mathrm{C}$ was much more sensitive than the assembly process at $37^{\circ} \mathrm{C}$ : the $30 \%$ reduction concentrations were $70 \mathrm{mM}$ and $0.25 \mathrm{mM}$ for assembly and disassembly, respectively, indicating a different mode of action.

\section{Diazepam}

Diazepam, a benzodiazepine, prolongs the lag-phase and has only little influence on the polymerization velocity and no effect on the steady state level, i.e. there is no reduction of the final amount of microtubules. Depending on the coordination of cellular processes a delay of the onset of microtubule formation might not only lead to a cell cycle delay but could also lead to serious disturbances of chromosome distribution.

Studies with diazepam in various aneuploidy test systems in vitro yielded equivocal results: chromosome maldistribution
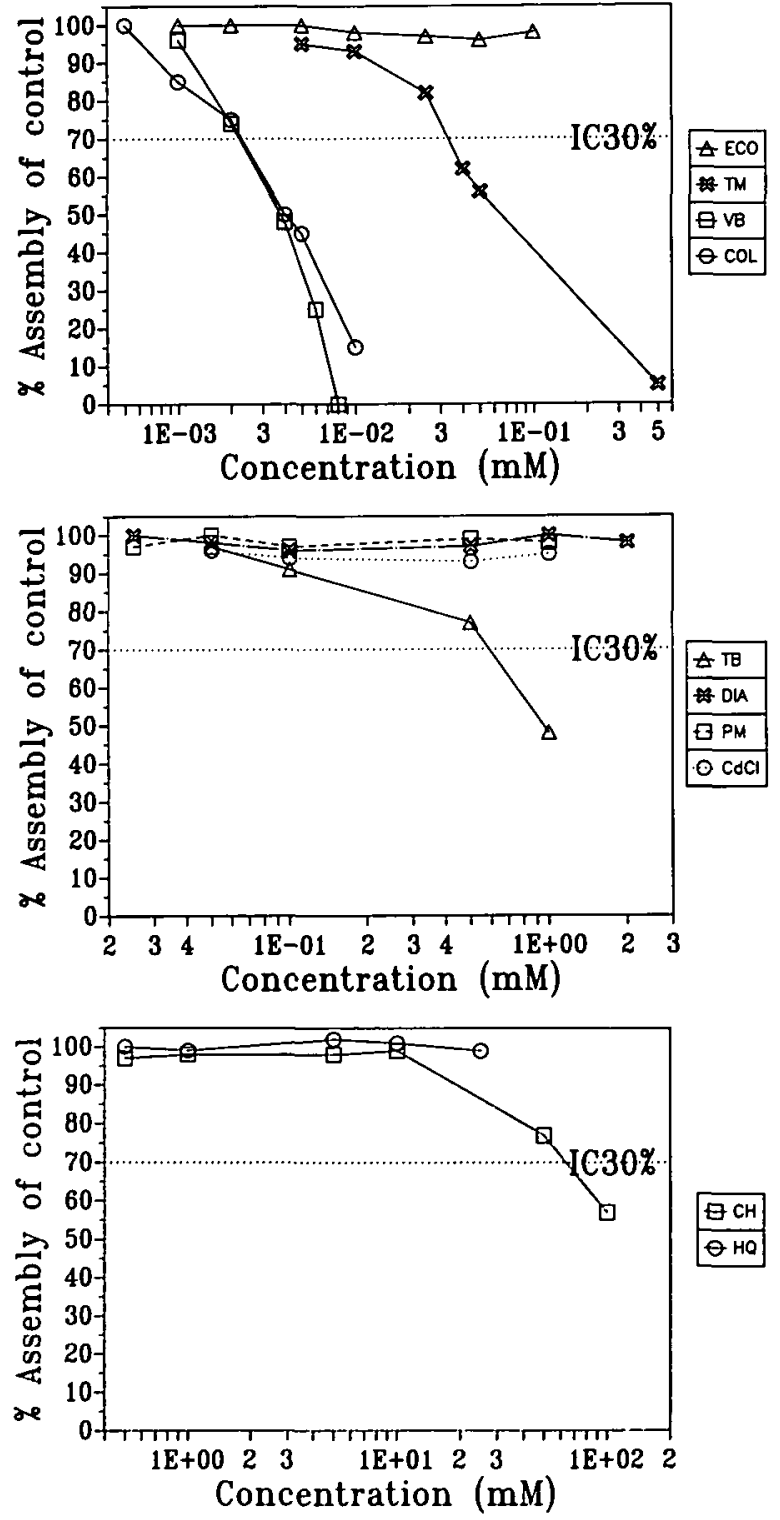

Fig. 2. Dose-dependent inhibition of the in vitro tubulin assembly by the 10 EEC aneuploidy core-chemicals. The percentage in comparison to the control (steady-state level $=100 \%$ ) is given. (a) ECO: econazole nitrate; TM: thimerosal; VB: vinblastine; COL: colchicine. (b) TB: thiabendazole; DIA: diazepam; PM: pyrimethamine; $\mathrm{CdCl}$ : cadmium chloride. (c) $\mathrm{CH}$ : chloralhydrate; HQ: hyroquinone. 


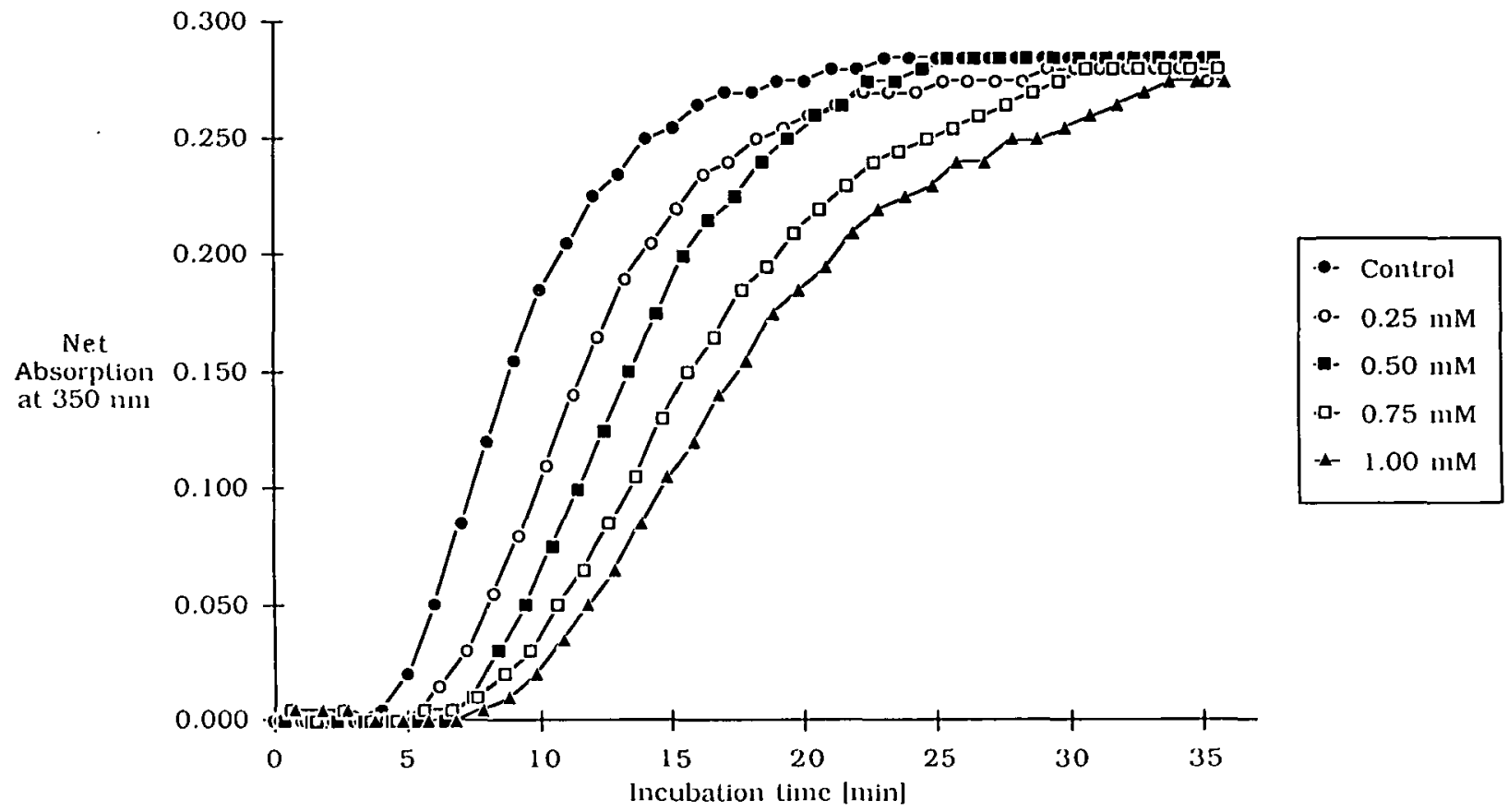

Fig. 3. Porcine brain tubulin assembly test with diazepam, Tubulin was incubated with different concentrations of diazepam.

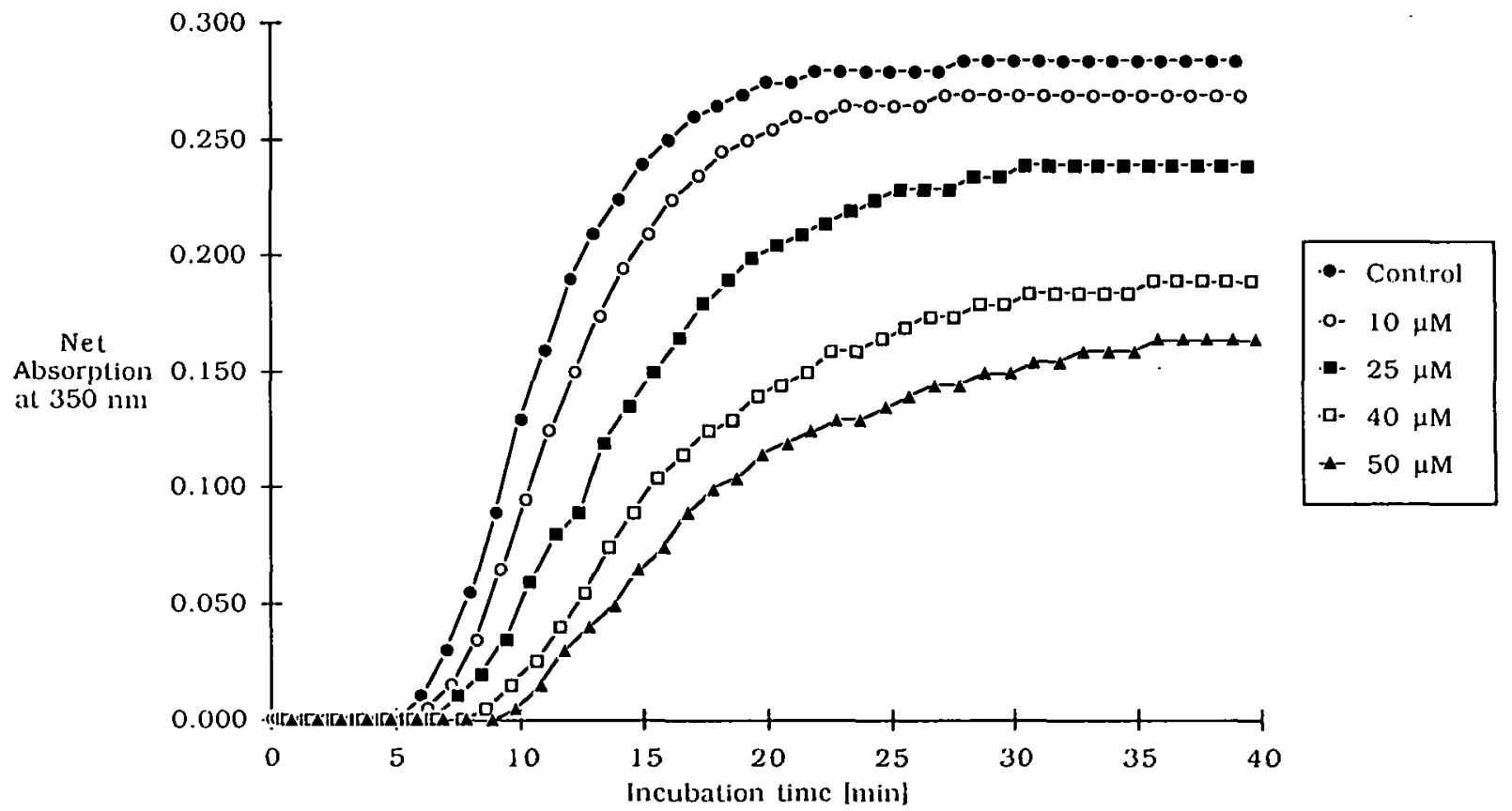

Fig. 4. Porcine brain tubulin assembly test with thimerosal. Tubulin was incubated with different concentrations of thimerosal.

and mitotic profile disturbances have been reported for various established cell lines (Anderson et al., 1981; Hsu et al., 1983a,b; Lafi et al., 1987; Lafi and Parry, 1988) whereas tests in S.cerevisiae D61.M were negative (Albertini, 1990). In vivo, in mouse bone marrow, no mitotic arrest or c-mitotic effects were observed at doses which clearly reduced bone marrow cell proliferation (Miller and Adler, 1989).

\section{Hydroquinone}

Hydroquinone (metabolite of benzene) was reported to inhibit the assembly of rat brain tubulin (Irons and Neptun, 1980; Irons et al., 1981). In contrast to these findings no effect on the assembly of porcine brain tubulin was observed by us. This discrepancy might be attributable to the ue of glycerol, which is believed to modify the native properties (Dustin, 1984).

\section{Thiabendazole}

Thiabendazole belongs to an interesting group of microtubule poisons, the benzimidazole derivatives. The biochemical basis of action is still poorly understood for benzimidazole compounds. With regard to susceptibility for mammalian and yeast tubulin, large variations in the binding properties were observed (Kilmartin, 1981). Nocodazole showed nearly identical affinity for mammalian and yeast tubulin, while bavistan showed $\sim 3000$-fold stronger binding to yeast tubulin. The $\mathrm{IC}_{30}$ of thiabendazole $(0.5 \mathrm{mM})$ for porcine brain tubulin is intermediate 


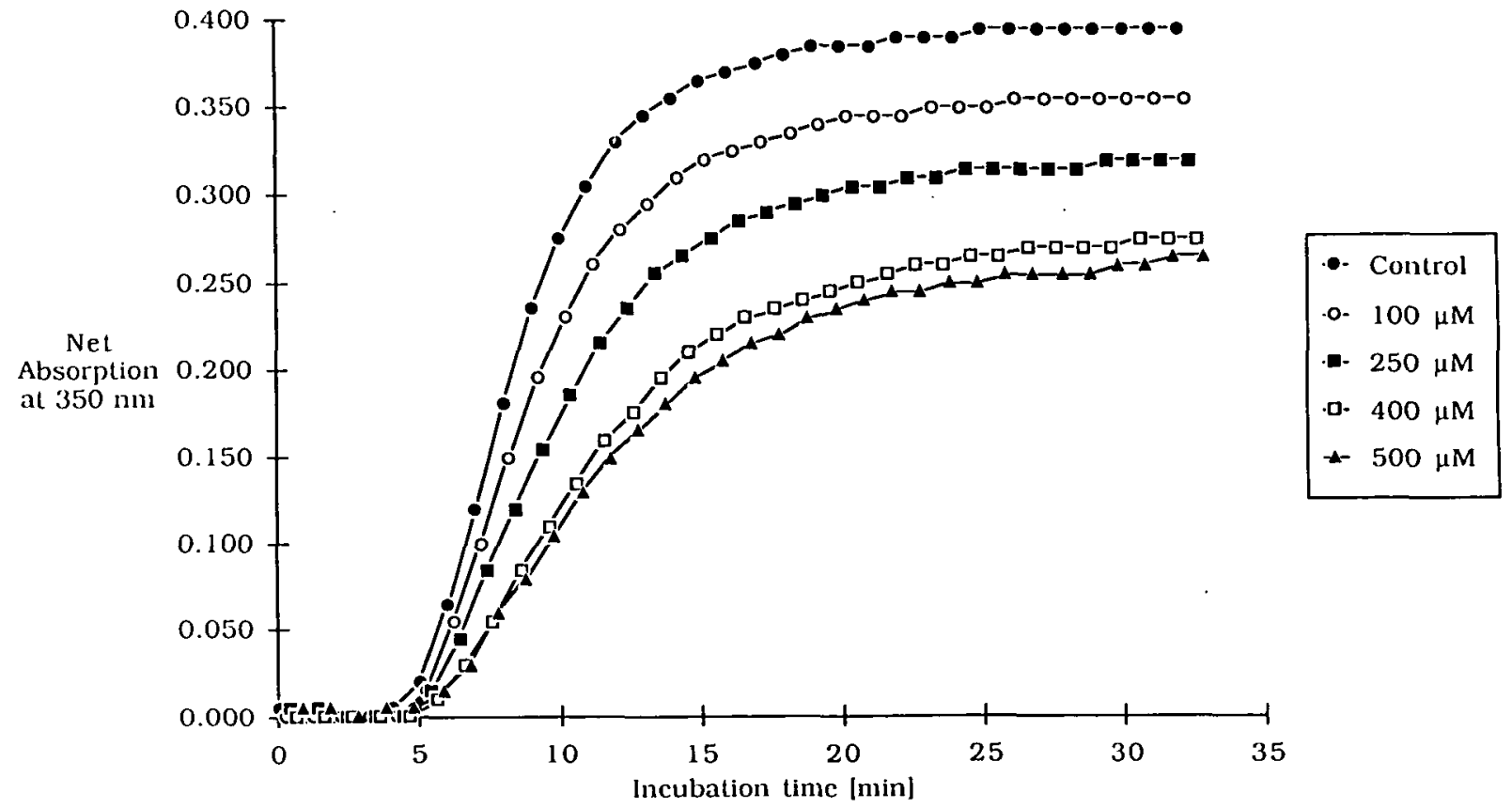

Fig. 5. Porcine brain tubulin assembly test with thiabendazole. Tubulin was incubated with different concentrations of thiabendazole.

to those of noncodazole $(0.007 \mathrm{mM})$ and bavistan $(>1.3 \mathrm{mM})$. The affiity of thiabendazole to yeast tubulin has not been reported, but since all three compounds are active in S.cerevisiae D61.M in the dose range $2-25 \mu \mathrm{g} / \mathrm{ml}$ it is likely that-like bavistanthiabendazole shows a preferential binding to yeast tubulin.

\section{Thimerosal}

Thimerosal, a organic mercury compound shows a relatively low $\mathrm{IC}_{30}$ of $0.03 \mathrm{mM}$. Organic mercury compounds are known to bind to sulfhydryl residues on tubulins and prevent polymerization. Thimerosal affects all three parameters investigated during the assembly process resembling the properties of well known microtubule poisons (colchicine, vinblastine).

\section{Conclusion}

We were able to show that microtubules are fairly easy to prepare and can be used as a simple screening object to study the effects of chemicals on assembly-disassembly processes.

Although no conclusive evidence of aneuploidy induction can be obtained from such in vitro tests alone, the in vitro tubulin assay can be used to pinpoint those chemicals which lead to cytoxicity and/or aneuploidy by inhibiting microtubule assembly.

A specific determination of the mode of action will become possible after detailed characterization of the interactions between chemicals and the individual protein components of the tubulin assembly system. This knowledge may allow predictions as to the in vitro effects of the test chemicals. In the work presented here apparently three basically different modes of actions can be distinguished: Diazepam enhances predominantly the lagphase, thimerosal all three parameters (lag-phase, polymerization velocity and steady state) and thiabendazole the polymerization velocity and the steady-state level but not the lag-phase.

Although only a small database is available at present, the in vitro tubulin assay seems well capable of determining those chemicals inducing aneuploidy via interactions with spindle proteins, and thereby allowing the differentiation of aneuploidy inducing agents acting on spindle components and those acting via other mechanisms.
Table II. Posible mechanisms (Liang and Brinkley, 1985), in vitro tubulin assembly assay results and results obtained in S.cerevisiae D61.M (Albertini, 1990).

\begin{tabular}{|c|c|c|c|}
\hline Chemical & Possible mechanism & $\begin{array}{l}\text { Tubulin } \\
\text { assay }\end{array}$ & $\begin{array}{l}\text { Yeast } \\
\text { assay }\end{array}$ \\
\hline Colchicine & Tubulin polumerization & + & - \\
\hline Econazole nitrate & Membrane effects & - & - \\
\hline Chloral hydrate & Spindle elongation & + & + \\
\hline $\begin{array}{l}\text { Hydroquinone } \\
\text { (benzene metabolite) }\end{array}$ & - & - & \\
\hline Diazepam & Centrioles/centromeres & - & - \\
\hline Thiabendazole & Tubulin polymerization & + & + \\
\hline Cadmium chloride & Enzyme systems & - & - \\
\hline Thimerosal & Microtubule assembly & + & + \\
\hline $\begin{array}{l}\text { Pyrimethamine } \\
\text { (pyrimidine base } \\
\text { analogue) }\end{array}$ & - & - & - \\
\hline Vinblastine & Tubulin crystallization & + & NT \\
\hline
\end{tabular}

\section{References}

Albertini,S. (1990) Analysis of 9 known or suspected spindle poisons for miotic chromosomal-malsegregation using Saccharomyces cerevisiae D61.M. Mutagenesis, 5, 453-459.

Albertini,S., Friederich,U., Gröschel-Stewart,U., Zimmermann,F.K. and Würgler,F.E. (1985) Phenobarbital induces aneuploidy in Saccharomyces cerevisiae and stimulates the assembly of porcine brain tubulin. Mutat. Res., 144, 67-71.

Albertini,S., Friederich,U. and Würgler,F.E. (1988a) Induction of chromosome loss in the diploid yeast Saccharomyces cerevisiae D61.M by genotoxic carcinogens and tumor promoters. Environ. Mol. Mutagenesis, 11, 497-508.

Albertini,S., Friederich,U., Holderegger,C. and Würgler,F.E. (1988b) The in vitro porcine brain tubulin assembly assay: effects of a genotoxic carcinogen (aflatoxin $\mathrm{B}_{1}$ ), eight tumor promoters and nine miscellaneous substances. Mutat. Res., 201, 283-292.

Albertini,S., Friederich,U. and Würgler,F.E. (1989) Reversible inhibition of mammalian tubulin assembly in vitro and effects in Saccharomyces cerevisiae D61.M by mitomycin C. Mutagenesis, 4, 39-44.

Anderson,L.C., Letho,V.-P., Stenman,S., Bradley,R.A. and Virtanen,I. (1981) Diazepam induces mitotic arrest at prometaphase by inhibiting centriolar separation. Nature, 291, 247-248.

Bradford,M.M. (1976) A rapid and sensitive method for the quantitation of 
microgram quantities of protein utilizing the principle of protein-dye binding. Anal. Boichem., 72, 248-254

Dustin,P. (1984) Microtubules, 2nd edn. Springer Verlag, Berlin.

Evans,L., Mitchison,T. and Kirschner,M. (1985) Influence of the centrosome on the structure of nucleated microtubules. J. Cell Biol., 100, 1185-1191.

Gaskin,F. (1982) Techniques for the study of microtubule assembly in vitro. Methods Enzymol., 85, 433-439.

Gröschel-Stewart,U., Mayer,V.W., Taylor-Mayer,R.E. and Zimmermann,F.K. (1985) Aprotic polar solvents inducing chromosomal malsegregation in yeast interfere with the assembly of porcine brain tubulin in vitro. Mutat. Res., 149 , $333-338$.

Hartley-Asp,B., Deinum,J. and Wallin,M. (1985) Diethylstilbestrol induces metaphase arrest and inhibits microtubule assembly. Mutat. Res., 143, $231-235$

Hook,E.B. (1983) ICPEMC working paper 5/3: Perspectives in mutational epidemiology: 3 . Contribution of chromosome abnormalities to human morbidity and mortality and some comments upon surveillance of chromosome mutation rates. Mutat. Res., 114, 389-423.

Hook,E.B. and Hamerton,J.L. (1977) The frequency of chromosome abnormalities detected in consecutive newborn studies-differences between studies-results by sex and by severity of phenotypic involvement. In Hook,E.B. and Porter,I.H. (eds), Population Cytogenetics: Studies in Humans. Academic Press, New York, pp. 63-79.

Hsu,T.C., Liang,J.C. and Shirley,R.L. (1983a) Aneuploidy induction by mitotic arrestants. Effects of diazepam on diploid Chinese hamster cells. Mutat. Res., 122, $201-209$

Hsu,T.C., Shirley,L.R. and Takanari,H. (1983b) Cytogentic assays for mitotic poisons: The diploid Chinese hamster cell system. Anticancer Res., 3, 155-160.

Irons,R.D. and Neptun,D.A. (1980) Effects of the principal hydroxy-metabolites of benzene on microtubule polymerisation. Arch. Toxicol., 45, 297-305.

Irons,R.D., Neptun,D.A. and Pfeifer,R.W. (1981) Inhibition of lymphocyte transformation and microtubule assembly by quinone metabolites of benzene: evidence for a common mechanism. J. Retinculoenthothelial Soc., 30, 359-372

Jacobs,P.A. and Hasold,T.J. (1980) The origin of chromosome abnormalities in spontaneous abortion. In Porter,I.H. and Hook,E.B. (eds), Human Embryonic and Fetal Death. Academic Press, New York, pp. 289-298.

Kilmartin,V. (1981) Purification of yeast tubulin by self-assembly in vitro. Biochemistry, 20, 3629-3633.

Kondo,K., Chilcote,R.R., Maurer,H.S. and Rowley,J.D. (1984) Chromosome abnormalities in tumor cells from patients with sporadic Wilms' tumor. Cancer Res., 44, 5375-5381.

Lafi,A. and Parry,J.M. (1988) A study of the induction of aneuploidy and chromosome aberrations after diazepam, medazepam, midazolam and bromazepam treatment. Mutagenesis, 3, 23-27.

Lafi,A., Parry,E.M. and Parry,J.M. (1987) The effects of benzodiazepines upon the fidelity of mitotic cell division in cultured Chinese hamster cells. Mutat. Res., 189, 319-332.

Laemmli,U.K. (1970) Cleavage of structural proteins during the assembly of the head of bacteriophage T4. Nature, 227, 680-685.

Laemmli,U.K. and Favre,M. (1973) Maturation of the head of bacteriophage T4. J. Mol. Biol., 80, 575-599.

Liang,J.C. and Brinkley,B.R. (1985) Chemical probes and possible targets for the induction of aneuploidy. In: Dellarco,V.L., Voytek,P.E. and Hollaender,A (eds), Aneuploidy, Etiology and Mechanisms. Basic Life Sciences, Vol. 36. Plenum Press, New York, pp. 491-505.

Miller,B.M. and Adler,I.-D. (1989) Suspect spindle poisons: analysis of c-mitotic effects in mouse bone marrow cells. Mutagenesis, 4, 208-215.

Parry,J.M. (1987) The validation of test systems for the detection of chemicals capable of inducing numerical chromosome aberrations. Mutagenesis, 2, 309.

Parry,J.M., Parry,E.M., Warr,T., Lynch,A. and James,S. (1990) The detection of aneugens using yeasts and cultured mammalian cells. Prog. Clin. Biol. Res., 340, 247-266.

Sankaranarayanan,K. (1979) The role of non-disjunction in aneuploidy in man: an overview. Mutat. Res., 61, 1-28.

Sharp,D.C. and Parry,J.M. (1985) Diethylstilboestrol: the binding and effects of diethylstilboestrol upon the polymerization and depolymerization of purified microtuble protein in vitro. Carcinogenesis, 6, 865-871.

Timasheff,S.N. (1979) The in vitro assembly of microtubules from purified brain tubulin. Trends Biochem. Sci., 61-65.

Tsutsui,T., Maizumi,H., McLachlan,J.A. and Barrett,J.C. (1983) Aneuploidy induction and cell transformation by diethylstilboestrol: A possible chromosomal mechanism in carcinogenesis. Cancer Res., 43, 3814-3821.

Wallin,M., Frideń,B. and Billger,M. (1988) Studies of the interaction of chemicals with microtubule assembly in vitro can be used as an assay for detection of cytotoxic chemicals and possible inducers of aneuploidy. Mutat. Res., 201, $303-311$.
Waters,M.D., Stock,K.H., Mavounin,K.H. and Dellarco,V.L. (1986) Genetic profiles of chemicals selected from the aneuploidy data base. Mutat. Res., 167, $171-188$.

Williams, R.C. and Lee,J.C. (1982) Preparation of tubulin from brain. Methods Enzymol., 85, 376-385.

Xu,W. and Adler,I.-D (1990) Clastogenic effects of known and suspected spindle poisons studies by chromosome analysis in mouse bone marrow cells. Mutagenesis, 5, 371-374.

Zimmermann,F.K., Mayer,V.W., Scheel,I. and Resnick,M.A. (1985a) Aceton, methyl ethyl keton, ethyl acetate, acetonitrile and other polar aprotic solvents are strong inducers of aneuploidy in Saccharomyces cerevisiae. Mutat. Res., $149,339-351$

Zimmerman,F.K., Gröschel-Stewart,U., Scheel,I. and Resnick,M.A. (1985b) Genetic change may be caused by interference with protein-protein interactions. Mutat. Res., 150, 203-210.

Zimmermann,F.K., Henning,J.H., Scheel,I. and Oehler,M. (1986) Genetic and anti-tubulin effects induced by pyridine derivatives. Mutat. Res., 163, 23-31.

Received on July 3, 1990; accepted on October 12, 1990 